IMAGE

UNAVAILABLE

FOR COPYRIGHT

REASONS

\title{
Emerging physics
}

\section{A fresh approach to viewing the complexity of the Universe.}

\section{A Different Universe: Reinventing Physics from the Bottom Down by Robert Laughlin}

Basic Books: 2005. 304 pp. \$26, £19.99

\section{Philip Anderson}

I should make my interests clear right at the start. For many years I have thought that a book such as this should be written, and have been urged to write it myself. I didn't do so, and couldn't possibly have written one as suited as this is for its target audience. A Different Universe is a book about what physics really is; it is not only unique, it is an almost indispensable counterbalance to the recent proliferation of books by Brian Greene, Stephen Hawking and their fellows, who promulgate the idea that physics is a science predominantly of deep, quasi-theological speculations about the ultimate nature of things. The enterprise of writing this book has my strong endorsement, then, and any disagreements or criticisms should be read in that light.

The central theme of the book is the triumph of emergence over reductionism: that large objects such as ourselves are the product of principles of organization and of collective behaviour that cannot in any meaningful sense be reduced to the behaviour of our elementary constituents. Large objects are often more constrained by those principles than by what the principles act upon. The underlying laws of physics have no sense of time, give us no clue either to measuring or locating ourselves in space, and provide no clue to identity - we are all made up of nothing but waves in a nonexistent medium (an analogy that Robert Laughlin draws from Christina Rossetti's poem Who Has Seen the Wind?). Our identity and perceptions are all the collective behaviour of 'ghosts', who borrow their reality from each other.

Laughlin gives the reader a quick tour through much of physics (without a single equation). There is a slight emphasis on the quantum theory of condensed matter, in so far as it explains such things as computers (with a sceptical side glance at quantum computation), the properties of ordinary metals, and the like. There is an enlightening discussion of the special quantum phenomena, the Hall and Josephson effects, which through the 'protection' of collective behaviour allow the measurement of Planck's constant and electric charge with enormous accuracy. The term 'protection' was coined by Laughlin and David Pines to express the fact that precise behaviours of large objects can result from, and even benefit from, disorderly behaviour at the atomic level. Some of this will be hard for the layman to follow, but at almost no point is it out of his reach. The pedagogy is leavened by anecdotes, occasional eloquence, and characteristically pungent diction (Laughlin once interrupted a scientific talk with "Liar, liar, pants on fire!").

There are idiosyncratic views of a wide variety of scientific topics. Laughlin reveals his view of nanotechnology with a chapter entitled "Carnival of the baubles" (a view with which one can concur). He gives us some inside information on the Star Wars defence project and its notoriously fraudulent X-ray laser weapon. He continues, comparing unfavourably the 'nanobaubles' of technology with those of life, the biomolecules, for which he has considerable admiration. Then we hear his own ideas on biology, which will not be to everyone's taste but are certainly thoughtprovoking. Finally, his view of complexity science surprised and pleased me with its relative benevolence.

Despite the above fulsome praise, this is not by any means a perfect book, even for its purpose. Laughlin is not reliably careful with facts, whether scientific or historical. For example, it has rhetorical value to give his great hero (and winner of two Nobel prizes) John Bardeen mythic status, and to demonize the "engineer" William Shockley, but this is incorrect. Shockley was verifiably contrary and sometimes mean, but he was also a great physicist. It was Shockley, rather than Bardeen, who was responsible for creating the great research centre at Bell Labs with James Fisk and Mervin Kelly. He also hired Bardeen, as well as many of the other stars who graced the place, such as Charles H. Townes, Conyers Herring and Bernd Matthias. Bardeen was human, and was wrong as often as he was right. It would have been instructive to point out that he published two mistaken theories of superconductivity 15 and 7 years before he got the right one. Laughlin's history and emphases are too much those of his generation.

Laughlin makes too much of the role of the renormalization group - a way of averaging out and getting 'universal' properties at the macroscopic level from the messy microscopic details - and other protection principles, as opposed to mechanism, in determining the properties of things. Was it 
Pierre Weiss, with his mysterious molecular field and Weiss magnetons, who explained ferromagnetism? Or was it, as I believe, Werner Heisenberg, with quantum theory? Laughlin misleadingly accuses two unnamed physicists of predicting that superconductors be limited to below $30 \mathrm{~K}$ (the actual figure was $40 \mathrm{~K}$ ), when what they said applied specifically to a particular mechanism for which it is true.

In my experience, which incidentally is greater than Laughlin's, underlying causes often enlighten our conceptual thinking as much as precise numbers do, something that Laughlin seems to deny. After condemning astroparticle types for overemphasizing deep thoughts and broad vistas, he seems to reveal a certain measure of 'particle envy' and distaste for the messy, quarrelsome but absorbing ways of doing the sciences in the real world. What made Bardeen great, as indeed he was, was his stubbornness and experimental taste, and Laughlin dismisses these values.

Those who devour the work of Greene, or decorate their coffee table with Hawking, will find this book a useful antidote. It should spike the interest of those who read the physics popularizers, although in its personalized coverage and opinionated style it is sui generis. My message is this: buy the book. Philip Anderson is in the Condensed Matter Physics Group, Department of Physics, Princeton University, Princeton, New Jersey 08544, USA.

\section{Don't talk to the animals}

\section{Doctor Dolittle's Delusion: Animals and the Uniqueness of Human Language \\ by Stephen R. Anderson \\ Yale University Press: 2004. 368 pp.

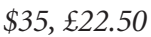

\section{Neil Smith}

Doctor Dolittle was the hero of a series of children's books written by Hugh Lofting (1886-1947). The doctor's ability to talk to every animal in its own language had a seductive appeal that finds current expression in the widespread belief that the communication systems of animals, from bees to bonobos, are essentially similar to human language. So we should be able to learn their languages or, just as good, they could learn ours. Stephen Anderson pours cold water on this belief, arguing convincingly that it is a delusion.

He provides a masterly overview of what is currently known about the communicative abilities of a wide range of creatures: the dance of honeybees, the communicative croaking of frogs, the warning cries of monkeys, and the remarkable cognitive abilities of bonobos and parrots. Much of this is superficially familiar from other popular accounts, but Anderson's synthesis provides illuminating comparisons with the infinitely more sophisticated resources of human language, whether spoken or signed. There are undeniable parallels between humans and other animals, but the differences are equally striking and confirm the view that our language is qualitatively different from theirs.

Bees famously indicate the direction, distance and quality of sources of pollen to their fellow workers by means of a 'waggle dance', which is often taken to show that they have a 'cognitive map' of the local terrain. In a meticulous dissection of the properties of this dance, Anderson undermines this claim, showing that the bees' perception of distance is largely a function of differences in their visual experience. When bees are made to fly through tunnels with visual patterns on the walls, the distance they indicate corresponds to the complexity of the pattern to which they have been exposed. The dance, then, reflects the bees' subjective experience, rather than a map of the external world.

We are evolutionarily rather remote from bees; closer parallels to human language and how we learn it can be found in birds. Current views of first-language acquisition in children treat it as a process of selection, rather than instruction. Humans are born with a set of principles known as 'universal grammar' that define the notion of possible

\section{Exhibition}

\section{Hirst's hobbit}

The maxim that the best science possesses an artistic grace has probably never been applied to the down-and-dirty world of palaeontology. First there's all the digging, and then there's the arguing over how the fragmentary findings should be interpreted and slotted into the big picture. But a new painting by Damien Hirst, A New and Diminutive Species of Human Being Has Been Discovered, brings the face of Homo floresiensis (the 'hobbit') — one of palaeontology's most iconic recent images to the gallery.

Photorealism - the painstakingly faithful reproduction of photographic images on canvas - is a surprising new direction for Hirst, arguably the doyen of the laddish Britart scene of the 1990s. Better known for pickling animals inside glass boxes, he has often engaged with science before. One of his trademark 'dot paintings' travelled to Mars aboard the ill-fated Beagle 2 lander and, given a smoother landing, would have been used to calibrate the craft's onboard cameras.

Hirst's other photorealist creations include images of the Iraq conflict, vivisection and a haunting reproduction of a British police anti-drugs campaign poster featuring the gaunt features of a now-dead crack addict. But what inspired him to take on $\mathrm{H}$. floresiensis,

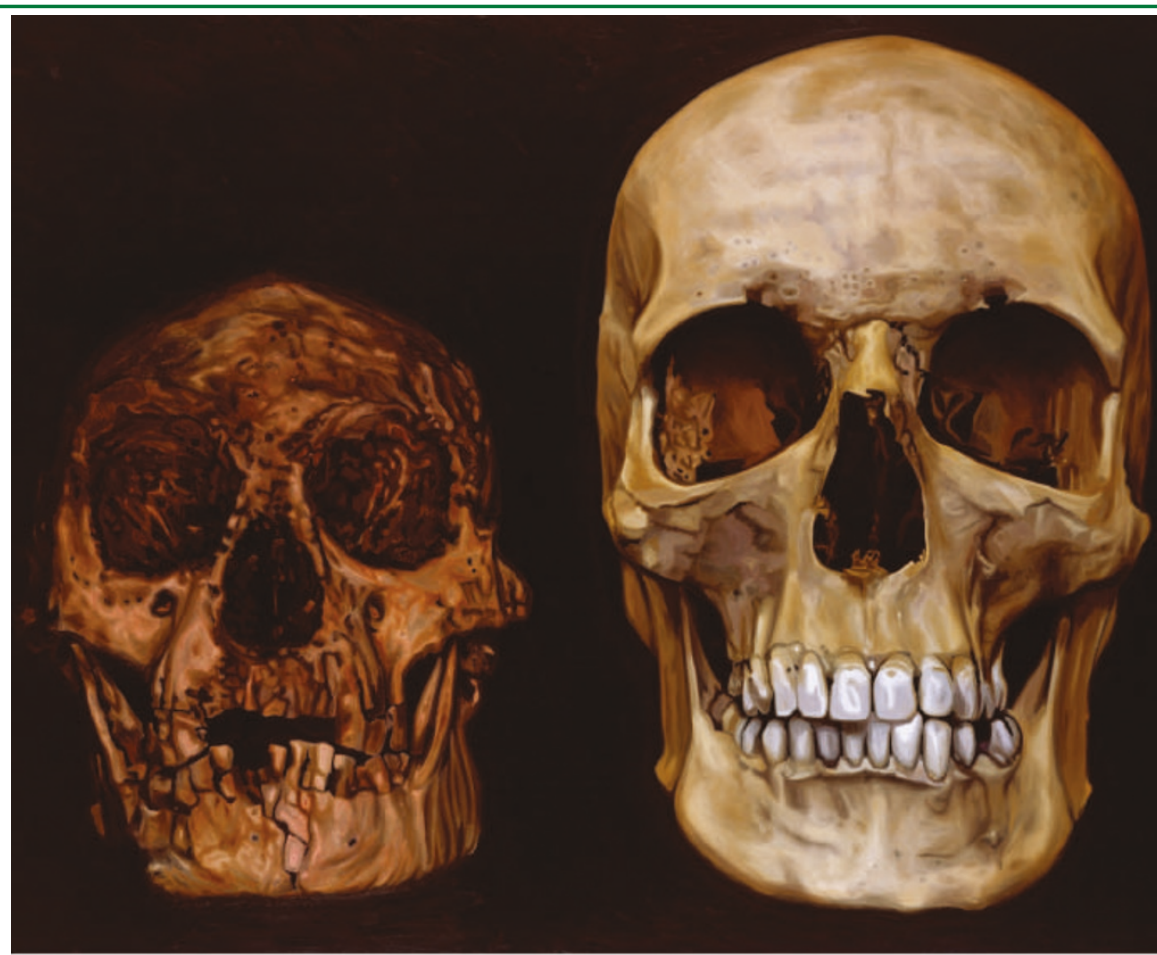

unveiled in Nature last October? "It's just an excuse to paint skulls," he says. Perhaps, but the hobbit's discoverers may nonetheless be amused to see the fruit of their labours raised to an art form.
A New and Diminutive Species of Human Being Has Been Discovered is part of the exhibition 'The Elusive Truth', which can be seen at the Gagosian Gallery in New York until 23 April. 
human language and a set of parameters that characterize possible variation among languages. The acquisition of language consists largely of fixing the values of these parameters on the basis of clues in the input. Importantly, this theory predicts that there are logically possible, but linguistically impossible, mistakes that children cannot make.

The parallel with birdsong is striking. Many birds have songs that develop appropriately only after interaction with conspecifics: the song is partly innate and partly dependent on experience. Nightingales, like children, only make mistakes that correspond to patterns that could occur as possible song elements for their species, just as children only make mistakes that are licensed by universal grammar.

We are evolutionarily closer to birds than to bees, but we are closer still to other primates. Their systems of communication, however, are less similar to human language than is popularly supposed. Vervet monkeys have distinct alarm calls for leopards, eagles and snakes. These calls can be extended to new types of threat - humans, for instance - and they are under some degree of voluntary control, yet they do not seem to 'refer' to the respective animals in the way we refer with our language. The calls can affect behaviour but not knowledge. Similarly, attempts to teach American Sign Language to chimpanzees have made it clear that, although human infants read intentions into the actions of others, chimps never do.

IMAGE

UNAVAILABLE FOR COPYRIGHT REASONS

\section{Aventis Science Book Prize shortlist announced}

The Royal Society has announced the shortlist for this year's Aventis Prizes for Science Books' General Prize, which celebrates the very best in popular science writing for adults.

Critical Mass by Philip Ball (William Heineman) takes a look at the application of physics to the collective behaviour of society. "This book is impressively clear and breathtaking in scope... For anyone who would like to learn about the intellectual ferment at the surprising junction of physics and social science, Critical Mass is the place to start." Steven Strogatz (Nature 428, 367-368; 2004).

Robert Winston's The Human Mind (Bantam Press/Transworld) is an examination of the workings of our brains for an adult audience, inspired by his recent television series. His book What Makes Me, Me? (Dorling Kindersley),
To complement his critique of 'animal language', Anderson also outlines what is special about human language: in a word, syntax. Our vocabularies are dramatically larger than those of other animals, and our sound systems are more complex, but the essential design property of human language is syntax - the way we use combinations of words to convey meaning. This concept is alien to the communication systems of other species.

What animals learn is impressive and their cognitive abilities may be remarkable. But they never master anything like a human language and seem incapable of doing so: the complexity of their grammar is not remotely comparable to ours. This complexity is exemplified at length in the book, but two examples should suffice. First, the essence of syntax is recursion: the possibility of including one sentence inside another ad infinitum. For example: [Anderson discusses the claim that [many people think that [animals can talk]]]. Second, we all have subtle and consistent intuitions not only of what is possible in our language, but also of what is impossible. In [John expects to visit him], "John" and "him" must refer to different people, but consider this: [I wonder who [John expects to visit him]]. Here, "John" and "him" can, but need not, refer to the same individual. Judgements such as these have no parallel in the communication systems of other animals.

Anderson's elegant book contains a host of other insights and observations. He concludes that, just as the dance of bees, the song of birds and the calls of monkeys are unique to their respective species, so human language is unique to us.

Neil Smith is in the Department of Phonetics and Linguistics, University College London, Gower Street, London WC1E 6BT, UK. which takes a wider view of how the human body functions for a younger audience, has been shortlisted for the Junior prize.

In The Ancestor's Tale (Weidenfeld \& Nicolson), Richard Dawkins "views species as pilgrims marching into the past, joining each other genetically on a 3-billion-year journey to evolution's Canterbury: the first 'replicator'". Jerry Coyne (Nature 431, 903-904; 2004).

In Matters of Substance (Penguin, Allen Lane), Griffith Edwards presents a lucid account of drug use and control, taking the radical view that the effect of any drug is just as dependent on the social, historical and psychological context as on its chemical structure.

In The Earth (HarperCollins), Richard Fortey "offers a clear, graphic and entertaining exposition of the manner in which, over an eon, the observed geological phenomena have achieved their present state. And he forcefully reminds us that events remotely embedded in deep time may yet be highly relevant as determinants for the lifestyles of modern human communities." Gordon L. Herries Davies (Nature 428, 697-698; 2004).

A review of Why Life Speeds Up As You Get Older by Douwe Draaisma (Cambridge University Press), an examination of the nature of memory, will appear in next week's issue of Nature.

The General Prize judging panel consists of author Bill Bryson, who won in 2004, weather forecaster Lisa Burke, Sian Ede,who is a renowned authority on art and science interactions, neurophysiologist Mark Lythgoe, and poet Ruth Padel. The winners will be announced on 12 May 2005. 